\title{
A Study on Cyberbullying: Its Forms, Awareness and Moral Reasoning Among Youth
}

\author{
Zsa Zsa Tajol Asanan, Ibiwani Alisa Hussain”, Nooraneda Mutalip Laidey \\ Faculty of Business and Management, Asia Pacific University of Technology and Innovation, Kuala Lumpur, Malaysia \\ Email address: \\ luckz_sasa@yahoo.com (Z.ZZ. T. Asanan),dr.ibiwani@apu.edu.my (I. A. Hussain), aneda@apu.edu.my (N. M. Laidey) \\ ${ }^{*}$ Corresponding author
}

\section{To cite this article:}

Zsa Zsa Tajol Asanan, Ibiwani Alisa Hussain, Nooraneda Mutalip Laidey. A Study on Cyberbullying: Its Forms, Awareness and Moral Reasoning Among Youth. International Journal of Information and Communication Sciences. Vol. 2, No. 58, 2017, pp. 54-58.

doi: $10.11648 /$ j.ijics.20170205.11

Received: March 24, 2017; Accepted: April 14, 2017; Published: October 23, 2017

\begin{abstract}
This purpose of the study is to investigate forms, awareness and moral reasoning against cyberbullying among youth. The study used primary data which was obtained through self-administered survey questionnaire. A total of 120 questionnaires were distributed to three different universities to examine the behaviour of youth towards cyberbullying pattern. Descriptive, frequency and correlation analysis were carried out on the primary data gathered. Findings showed that the three independent variables have close relationship towards the activities of cyberbullying among youth.
\end{abstract}

Keywords: Awareness, Cyber Bullying, Forms, Moral Reasoning, Youth

\section{Introduction}

The modern technology which creates a borderless world had upgraded bullying into cyberbullying [1] and it is a prevalent issue that happens everywhere regardless of schools or the working world [2]. The word cyberbullying did not even exist before, yet it has becoming as one of a major issue nowadays. Cyberbullying can be defined as adolescent aggression through electronic communication [2]. It can also be defined as a repeated intentional aggression carried out by an individual or group of people using electronic forms such as chat rooms towards victim who does not have the ability to defend themselves [3, 4]. Cyberbullying is also defined as wilful and repeated harm inflicted through the use of computers, cells phones and other electronic devices [5] meanwhile [6] explained cyberbullying as a repetition of insult, hurt or harassing others using information technology. It is a systematic abuse of power which occurs through the use of information and communication technologies [7]. Many studies had been conducted among school children in the United States, however, similar study had not been conducted among university students. Therefore, this study is intended to investigate the level of awareness, the forms as well as moral reasoning of university students (hereinafter after known as youth) in Malaysia.

\subsection{Forms}

Cyberbullying is a build-up problem that has expanded with the growth of social hierarchy [8]. It can be traced back to normal bullying and now with the advancement of technology, bullying takes a new form which is cyberbullying. The forms cyberbullying are flaming, harassment, cyberstalking, impersonation, cyber threats and online harassment $[9,10]$. Through these forms, the bullies reach their victim through social media site, text messages and phone calls. Cyberbullying takes such forms because of the users' addictiveness towards the internet [11]. These people can only live with the internet because it is the only time they feel alive [12]. Going online gives them the feel of being in control and safer because the identity remains anonymous and they are in their comfort zone. Cyberbullying activities can be subcategorized into text messages bullying, pictures or video clips, phone call bullying, email bullying, chat-room bullying, bullying through instant messages or via websites [13]. Breakdown of cyberbullying helps people to understand which forms are most prevalent [13].

\subsection{Awareness}

Awareness of cyberbullying is faint among the society and 
cyberbullying is on the rise caused by the lack of knowledge and awareness in this issue. Awareness is an important factor for prevention sake as society are more aware of traditional bullying compared to cyberbullying [14]. The only difference is that it does not inflict physical injury but rather emotional disturbance which can do worse damages compare to physical wound. However, cyberbullying has been taking over the reign $[15,16]$. Awareness is still at minimal level and it had been confirmed by previous research $[14,17]$. Hence, it is believed that it needs to be understood by society including parents and teachers the potential of cyberbullying happening to their children. Merely installing filters on computers does not help in protecting them from unwanted contacts [18]. Most importantly, parents need to be aware that this unhealthy activity is happening around them. Hence, it is important for them to be aware of each subtype of cyberbullying [14]. The higher the awareness level among public is, the lower the statistics of cyberbullying case happening globally.

\subsection{Moral Reasoning}

Moral reasoning can be referred to as common sense and judgment. Kohlberg stated that there are six stages of moral development [19]. The theory of moral reason that was adopted back then was further classified into two new typologies [20]. The first is up-standers and the second is bystander. However, it was stated that the moral reasoning of a bystander and the up stander clouded upon only at the scenarios, the role play by the users, gender, emotion and contextual factors [20]. In contrast, another researcher [21] commented that moral reasoning means the public tolerance level towards cyberbullying activities, as well as how acceptive the public are towards the rules that regulate cyberbullying. Moral reasoning also depends on individuals' thoughts on how much can they accept and up to what extend do they consider cyberbullying as an unhealthy practice [21]. Moral judgement is made purely on emotion or affection rather than reason [20, 22, 23]. An interesting development in the theory of moral development [19] was the argument put forth by reference [20]. He argued that the stage of moral judgement can only be achieved by certain individual in a certain context based on their own ethical thoughts. The author suggested that moral reasoning is a dependent concept whereby different individuals express their morality differently than their personal needs and ability.

\section{Methodology}

The objective of this study is to study youths' responsiveness on cyberbullying predicted by forms, awareness and moral reasoning. The study adopts quantitative method using primary data gathered through self-administered survey questionnaire. The population for the data respondent are youth living in Malaysia. These youth were from three private universities in Malaysia of the age of 18-25. In terms of research design, this study used quota sampling methodology. Hence out of 120 questionnaires, 40 questionnaires were distributed at each university. Items used to measure the predictors of cyberbullying (i.e.: forms, awareness and moral reasoning) which were used in the survey questionnaires were adopted from 'An investigation into cyberbullying, its forms, awareness and impact, and the relationship between age and gender in cyberbullying' [13].

\section{Findings}

Table 1 shows a higher percentage of female respondent compared to male respondent which is denoted by $53 \%$ and $47 \%$ respectively. Out of the 120 respondents, $73 \%$ were Malaysian while the remaining were foreigners. Since cyberbullying happen through social media, there were a few general items used to measure the preference of social network, time spend on browsing through their social network account and most common platform utilized by youth.

Table 1. Gender \& Nationality.

\begin{tabular}{lc}
\hline Gender & \\
\hline Male & $47 \%$ \\
Female & $53 \%$ \\
Nationality & \\
Malaysian & $73 \%$ \\
Foreigner & $27 \%$ \\
\hline
\end{tabular}

The results shows the most popular social network is Facebook. 112 respondents have an account with Facebook and 87 respondents mentioned that they have YouTube account. While the least favourable social network is blog and only 7 respondents mentioned they are using it. Based on the popularity of social media among youth in this modern era, the research shows that, $39.2 \%$ of youth spend around 3 to 4 hours browsing through their social media account such as Facebook, YouTube and others per day. Internet browsing activities mostly happen via smartphone (81.7\%) compared to laptop and tablets.

Few predictors were used in the awareness section and level of awareness of cyber bullying among youth are summarised as: posting mean and hurtful pictures of others $(27.5 \%)$; mean and hurtful comments $(26.7 \%)$; spreading rumours about others (24.2\%); hacking into someone else account and pretending to be them (15.8\%); and threat to hurt someone (5\%). The level of awareness is worrying as many respondents are not aware that a threat to hurt someone is considered as cyber bullying as it can be seen that only $5 \%$ respondents agreed to this predictor and only one respondent $(0.83 \%)$ is fully aware that all of the predictors are considered as cyber bullying.

Table 2. Most Aware Forms of Cyberbullying.

\begin{tabular}{lll}
\hline & Frequency & Percent \\
\hline Mean or hurtful comments & 32 & 26.7 \\
$\begin{array}{l}\text { Spreading rumours about someone } \\
\text { Threats to hurt someone }\end{array}$ & 30 & 25.0 \\
$\begin{array}{l}\text { Hacking into my account and pretending to be } \\
\text { someone }\end{array}$ & 20 & 4.2 \\
$\begin{array}{l}\text { Posting mean and hurtful pictures or videos of } \\
\text { someone }\end{array}$ & 31 & 16.7 \\
$\begin{array}{l}\text { Other: In any form that hurt someone is cyber } \\
\text { bullying. All type. None excluded. }\end{array}$ & 1 & 25.8 \\
$\begin{array}{l}10.00 \\
\text { Total }\end{array}$ & 1 & .8 \\
\hline
\end{tabular}


In terms of awareness, 55\% respondents agreed and 30.8\% strongly agreed that they are aware of cyberbullying incidents/activities on the internet. $11.7 \%$ respondents were neutral about cyberbullying activities and a small, percentage $(2.5 \%)$ are not at all aware of cyber bullying activities.

Table 3. Awareness of Cyberbullying.

\begin{tabular}{lll}
\hline & Frequency & Percent \\
\hline Strongly Agree & 37 & 30.8 \\
Agree & 66 & 55.0 \\
Neutral & 14 & 11.7 \\
Disagree & 2 & 1.7 \\
Strongly Disagree & 1 & .8 \\
Total & 120 & 100.0 \\
\hline
\end{tabular}

Despite the respondents' awareness about cyberbullying activities, $50.8 \%$ of the respondents are a bystander (a person who sees something happens, without being involved in it) and the remaining $49.2 \%$ are an up stander (a person who sees a person bullied and stand up against bullies).

Table 4. Up stander/ Bystander.

\begin{tabular}{lll}
\hline & Frequency & Percent \\
\hline Up stander & 59 & 49.2 \\
Bystander & 61 & 50.8 \\
Total & 120 & 100.0 \\
\hline
\end{tabular}

A correlation analysis was conducted to examine the relationship between the forms of cyberbullying, the awareness of cyberbullying and moral reasoning of cyberbullying and cyberbullying [24] and to achieve this purpose, reference [25] guideline on correlation score was adopted. The guideline is described in this manner: the scale of small is $\mathrm{r}=.10$ to.29, medium is $\mathrm{r}=.30$ to.49, and large is $\mathrm{r}=.50$ to 1.0 .

Table 5. Correlation Test.

\begin{tabular}{|c|c|c|c|c|c|}
\hline & & Cyberbullying & Forms & Awareness & Moral Reasoning \\
\hline \multirow{3}{*}{ Cyberbullying } & Pearson Correlation & 1 & $.640^{* *}$ & $.809^{* *}$ & $.793^{* *}$ \\
\hline & Sig. (2-tailed) & & .000 & .000 & .000 \\
\hline & $\mathrm{N}$ & 120 & 120 & 120 & 120 \\
\hline \multirow{3}{*}{ Forms } & Pearson Correlation & $.640^{* *}$ & 1 & $.685^{* *}$ & $.706^{* *}$ \\
\hline & Sig. (2-tailed) & .000 & & .000 & .000 \\
\hline & $\mathrm{N}$ & 120 & 120 & 120 & 120 \\
\hline \multirow{2}{*}{ Awareness } & Pearson Correlation & $.809^{* *}$ & $.685^{* *}$ & 1 & $.841^{* *}$ \\
\hline & $\mathrm{N}$ & 120 & 120 & 120 & 120 \\
\hline \multirow{3}{*}{ Moral Reasoning } & Pearson Correlation & $.793^{* *}$ & $.706^{* *}$ & $.841^{* *}$ & 1 \\
\hline & Sig. (2-tailed) & .000 & .000 & .000 & \\
\hline & $\mathrm{N}$ & 120 & 120 & 120 & 120 \\
\hline
\end{tabular}

$* *$ Correlation is significant at the 0.01 level (2-tailed).

The correlation table above illustrates the relationship between the predictors and dependent variables. The first correlation: cyberbullying and the forms of cyberbullying shows a strong relationship where 0.64 was denoted. Next is the relationship between awareness on cyberbullying and cyberbullying activity and it was denoted at 0.809 . Here it can be revealed that there is a there is a significant level of relationship between the awareness of cyberbullying and cyberbullying compared to the first predictor. On the moral reasoning predictor, findings revealed that, it has significant relationship, valued at 0.793 . The value is higher compared to forms of cyberbullying but lower than the value of awareness on cyberbullying activity. The value of 0.793 indicated that there is a high significant level of relationship between moral reasoning of cyberbullying against cyberbullying activity.

\section{Discussion}

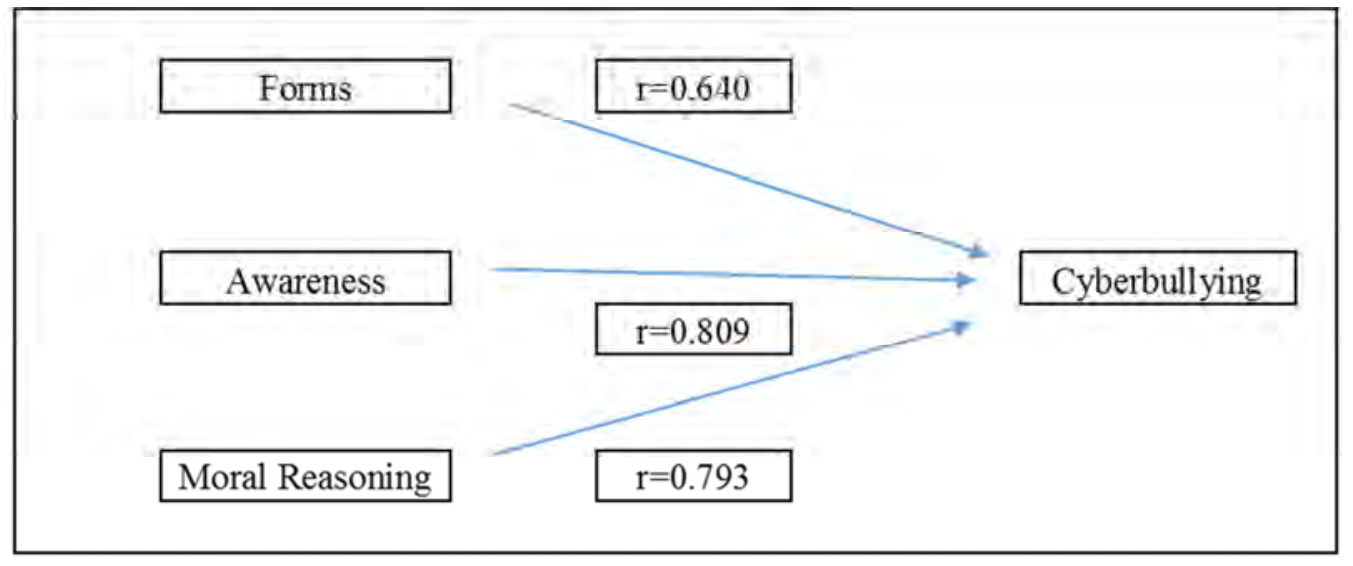

Figure 1. Correlation Test Findings. 
Based on the results obtained from correlation analysis, it can be described that there is a significant relationship between cyberbullying and the forms of cyber bullying. $64 \%$ respondents are familiar with the forms of cyberbullying. A study on cyberbullying conducted by other researcher also revealed similar results [13]. However, the previous studies were focusing more towards teenagers, between the ages of 12 to 20 years old. Findings from previous studies revealed that most of the students at a younger age know the pattern and forms of cyberbullying and picture and video clips were the highest form of cyberbullying performed by teenage respondents [26]. On a different note, a study by reference [27] found the opposite whereby there are many forms of cyberbullying that are actively going on among youth. The form of cyberbullying applied on their victims differs, depending on the reason as well as gender. In most of the cases, the victim of cyberbullying activities revolves among the youth who are within the younger generation [2]. Therefore it can be concluded that youth these days are familiar with the forms of cyberbullying.

Result from the correlation analysis shows that awareness of cyberbullying has a positive significant relationship towards cyberbullying activity among the youth. The findings showed the relationship is at 0.809 . This means that $80.9 \%$ of the respondents has the awareness of cyberbullying among youth in the cyber space. It is also found that those who have more awareness of cyberbullying activities appeared to be more supportive in helping the victim to voice out their distress [28]. Adults are becoming more aware of the signs of cyberbullying as to understand and prevent their children from becoming a victim of cyberbullying [29]. Results from survey showed that $47 \%$ of the sample size had witnessed cyberbullying activities while $11 \%$ admitted to being the bully and $29 \%$ stated that they were a victim of cyberbullying. In total, out of $100 \%$, $87 \%$ knows what is cyberbullying and cyberbullying activity and hence, there is a high level of awareness of cyberbullying activities among the sample size.

Moral reasoning has a positive significant relation with cyberbullying activities among youth (79.3\%). A study conducted by reference [30] found that age and gender are among the important factors for cyberbullies in choosing the victim. However, what is worrying is that youth who are involved in cyberbullying activities does not even morally aware that they are the bully [31]. Therefore, one way to increase the moral reasoning level among youth and encourage them to reduce cyberbullying activities is to educate them on many types of cyberbullying characteristics. Additionally, moral values can be instilled by creating cognizance amongst the public on the moral reasoning behind the activities of cyberbullying [32]. With the establishment of moral reasoning in a person, cyberbullying activities can be minimized [33]. The findings in this study revealed that victims of cyberbullying will usually experience high negative impact psychologically and most of the time caused the victim to lower their self-esteem [34, 35] and this activity is prevalent and has gaining its popularity amongst youth.

\section{Conclusion}

Cyberbullying is proven to be prevalent among youth and all of the predictors have a significant level of correlation with the independent variable. Even when it was proven that most youth have either witnessed cyberbullying or admitted to being the bully themselves, cyberbullying is still a predominant issue among youth. Then, we must go back to basics in which awareness is the key. However, individual self-concepts evaluate one's perception, moral believes, personal attributes, family life and social dimensions which can be powerfully affected by the judgement made by others. Finally, as recommendation, the sample size in this research cannot represent the total population. Therefore, it is recommended that the study is to be continued in a large scale. Another dimension can also be added to make this research more meaningful.

\section{References}

[1] Zhao, R., Zhou, A., \& Mao, K. (2016, January). Automatic detection of cyberbullying on social networks based on bullying features. In Proceedings of the 17th International Conference on Distributed Computing and Networking ( $\mathrm{p}$. 43). ACM.

[2] Notar, C. E., Padgett, S., \& Roden, J. (2013). Cyberbullying: A review of the literature. Universal Journal of Educational Research, 1(1), 1-9.

[3] Dadvar, M., \& De Jong, F. (2012, April). Cyberbullying detection: a step toward a safer internet yard. In Proceedings of the 21st International Conference on World Wide Web (pp. 121-126). ACM.

[4] Sticca, F., \& Perren, S. (2013). Is cyberbullying worse than traditional bullying? Examining the differential roles of medium, publicity, and anonymity for the perceived severity of bullying. Journal of youth and adolescence, 42(5), 739750 .

[5] Hinduja, S., \& Patchin, J. W. (2009). Cyber Bullying Research Center Cyber bullying fact sheet: What you need to know about online aggression. [Online]. Available at $\mathrm{http}: / /$ www.cyberbullying.us/cyberbullying_fact_sheet.pdf [Accessed 25 January 2017].

[6] Squicciarini, A., Rajtmajer, S., Liu, Y., \& Griffin, C. (2015, August). Identification and characterization of cyberbullying dynamics in an online social network. In Proceedings of the 2015 IEEE/ACM International Conference on Advances in Social Networks Analysis and Mining 2015 (pp. 280-285). ACM.

[7] Slonje, R., Smith, P. K., \& FriséN, A. (2013). The nature of cyberbullying, and strategies for prevention. Computers in Human Behavior, 29(1), 26-32.

[8] Donegan, R. (2012). Bullying and cyberbullying: History, statistics, law, prevention and analysis. The Elon Journal of Undergraduate Research in Communications, 3(1), 33-42. 
[9] Aune, N. M. (2009). Cyberbullying. December 2009 (Doctoral dissertation, University of Wisconsin-Stout).

[10] Fegenbush, B. S., \& Olivier, D. F. (2009, March). Cyberbullying: A literature review. In Annual Meeting of the Louisiana Education Research Association, Lafayette.

[11] Ma, H. K. (2011). Internet addiction and antisocial Internet behavior of adolescents. The Scientific World Journal, 11, 2187-2196.

[12] Nilan, P., Burgess, H., Hobbs, M., Threadgold, S., \& Alexander, W. (2015). Youth, social media, and cyberbullying among Australian youth: "Sick friends". Social Media+ Society, 1(2), 2056305115604848.

[13] Smith, P. K., Mahdavi, J., Carvalho, M., \& Tippett, N. (2006). An investigation into cyberbullying, its forms, awareness and impact, and the relationship between age and gender in cyberbullying. Research Brief No. RBX03-06. London: DfES.

[14] Paullet, K., \& Chawdhry, A. A. (2012). Raising awareness: Education is the key to understanding cyberbullying. In Proceedings of the Information Systems Educators Conference $\operatorname{ISSN}$ (Vol. 2167, p. 1435).

[15] National Bullying Prevention Center, 2016. National Bullying Prevention Center. [Online] Available at: $\mathrm{http}: / /$ www.pacer.org/bullying/resources/stats.asp [Accessed 15 February 2017].

[16] Vervoort, M. H., Scholte, R. H., \& Overbeek, G. (2010). Bullying and victimization among adolescents: The role of ethnicity and ethnic composition of school class. Journal of youth and adolescence, 39(1), 1.

[17] Bauman, S. (2013). Cyberbullying: What does research tell us?. Theory Into Practice, 52(4), 249-256.

[18] Baldwin, M. M., Cirillo, K., Ferrigno, M. \& Argento, V., 2015. An Examination of Cyber-bullying and Social Media Use in Teens: Prevalence, Attitudes and Behaviors. Journal of Bullying \& Social Aggression, 1(1), pp. 1-5

[19] Kohlberg, L., \& Candee, D. (1984). The relationship of moral judgment to moral action. Morality, moral behavior, and moral development, 52, 73 .

[20] Graeff, E. (2014). Tweens, cyberbullying, and moral reasoning: Separating the upstanders from the bystanders. In Communication and Information Technologies Annual (pp. 231-257). Emerald Group Publishing Limited.

[21] Harrison, T. (2015). Virtuous reality: moral theory and research into cyber-bullying. Ethics and Information Technology, 17(4), 275-283.

[22] Haidt, J. (2001). The emotional dog and its rational tail: a social intuitionist approach to moral judgment. Psychological review, 108(4), 814.

[23] Greene, J. D., Sommerville, R. B., Nystrom, L. E., Darley, J. M., \& Cohen, J. D. (2001). An fMRI investigation of emotional engagement in moral judgment. Science, 293(5537), 2105-2108.

[24] Achelis, S. B., 2017.Technical Analysis from A to Z [Online]. Available at:

http://www.metastock.com/customer/resources/taaz/?c=3\&p= 44 [Accessed 25 January 2017].

[25] Pallant, J., 2011. SPSS Survival Manual, Australia: Allen \& Unwin.

[26] Slonje, R. \& Smith, P. K., 2008. Cyberbullying: Another main type of bullying?. Scandinavian Journal of Psychology, Volume 49, pp. 147-154.

[27] Tarapdar, S., \& Kellett, M. (2011). Young people's voices on cyber bullying: what can age comparisons tell us. Diana Awards.

[28] Nixon, C. L. (2014). Current perspectives: the impact of cyberbullying on adolescent health. Adolescent health, medicine and therapeutics, 5, 143.

[29] Ey, L. A., Taddeo, C., \& Spears, B. (2015). Cyberbullying and primary-school aged children: the psychological literature and the challenge for sociology. Societies, 5(2), 492-514.

[30] National Children's Bureau, 2016. Focus on: Cyberbullying, London: National Children's Bureau. http://www.antibullyingalliance.org.uk/media/38460/Focus-onCyberbullying.pdf

[31] Teasley, M. (2013). Cyberbullying, youth behavior and society. Journal of Child and Adolescent Behaviour, 2, 120.

[32] Harrison, T. (2016). Cultivating cyber-phronesis: a new educational approach to tackle cyberbullying. Pastoral Care in Education, 34(4), 232-244.

[33] Schultze-Krumbholz, A., Schultze, M., Zagorscak, P., Wölfer, R., \& Scheithauer, H. (2016). Feeling cybervictims' painThe effect of empathy training on cyberbullying. Aggressive behavior, 42(2), 147-156.

[34] Schneider, S. K., O'donnell, L., Stueve, A., \& Coulter, R. W. (2012). Cyberbullying, school bullying, and psychological distress: A regional census of high school students. American Journal of Public Health, 102(1), 171-177.

[35] Hoff, D. L., \& Mitchell, S. N. (2009). Cyberbullying: Causes, effects, and remedies. Journal of Educational Administration, $47(5), 652-665$. 